\title{
Review Article \\ The Carbon Nanotube Fibers for Optoelectric Conversion and Energy Storage
}

\author{
Yongfeng Luo, ${ }^{1} \mathrm{Xi} \mathrm{Li},{ }^{1}$ Jianxiong Zhang, ${ }^{1}$ Chunrong Liao, ${ }^{1}$ and Xianjun $\mathrm{Li}^{2}$ \\ ${ }^{1}$ College of Science, Central South University of Forestry and Technology, Changsha, Hunan 410004, China \\ ${ }^{2}$ Material Science and Engineering School, Central South University of Forestry and Technology, Changsha, Hunan 410004, China \\ Correspondence should be addressed to Xianjun Li; lxjmu@163.com
}

Received 25 April 2014; Accepted 31 May 2014; Published 21 August 2014

Academic Editor: Li Li

Copyright (c) 2014 Yongfeng Luo et al. This is an open access article distributed under the Creative Commons Attribution License, which permits unrestricted use, distribution, and reproduction in any medium, provided the original work is properly cited.

\begin{abstract}
This review summarizes recent studies on carbon nanotube (CNT) fibers for weavable device of optoelectric conversion and energy storage. The intrinsic properties of individual CNTs make the CNT fibers ideal candidates for optoelectric conversion and energy storage. Many potential applications such as solar cell, supercapacitor, and lithium ion battery have been envisaged. The recent advancement in CNT fibers for optoelectric conversion and energy storage and the current challenge including low energy conversion efficiency and low stability and future direction of the energy fiber have been finally summarized in this paper.
\end{abstract}

\section{Introduction}

Flexible and portable electronic devices have been extensively studied for a wide range of applications in solar cell [1-21], lithium ion battery [22, 23], supercapacitor [24-29], sensors [30], and their integrated device [31-36]. Weavable electronic devices usually require corresponding fiber materials to fabricate them. There is an increasing interest in flexible solar cells and researchers have been investigating weavable fiber solar cells based on metal wires, glass fibers, or polymer fibers [37-42]. Unfortunately, the low efficiencies of these fiberbased solar cells greatly limit their promising applications.

Carbon nanotubes have been widely introduced to fabricate high-efficiency organic solar cells because of their extremely high surface area (e.g., ca. $1600 \mathrm{~m}^{2} \mathrm{~g}^{-1}$ for singlewalled nanotubes) and superior electrical properties [43]. However, nanotubes are used in electrode materials. For example, the incorporation of nanotubes onto titania nanoparticle films has been shown to increase the roughness factor and decrease the charge recombination of electron/hole pairs [44], and the replacement of platinum with nanotubes as counter electrode catalyzed the reduction of triiodide to improve the cell performance. The distribution of nanotubes within the photoactive layer improved the short circuit current density and fill factor owing to rapid charge separation at the nanotube/electron donor interface and efficient electron transport through nanotubes [45]. However, the degrees of improvement are far from what is expected for nanotubes, mainly because of random aggregation of nanotubes in the cells. For a random nanotube network, the electrons have to cross many more boundaries. Therefore, alignment of nanotubes will further greatly improve cell performance as charge transport is more efficient. To improve the practical application of CNTs, scientists are exploring various nanomaterials to improve charge separation and transport in these fiber-based photovoltaic devices. Researchers aligned continuous multiwalled CNT sheets and fibers to produce materials with high mechanical strength and electrical conductivity; it is critically important to extend their physical properties from the nanoscale to the macroscopic scale. The excellent mechanical and electrical performance of individual CNTs make the CNT fibers ideal candidates for optoelectric conversion and energy storage.

CNT fibers can be fabricated directly from chemical vapor deposition (CVD) [50] or can be spun from highquality aligned CNT arrays [1, 2, 51-53]; Li and coauthors [50] spun fibers and ribbons of CNTs directly from CVD synthesis zone of a furnace using a liquid source of carbon and an iron nanocatalyst. This process was realized through the appropriate choice of reactants, control of the reaction conditions, and continuous withdrawal of the product with a rotating spindle used in various geometries. This direct 


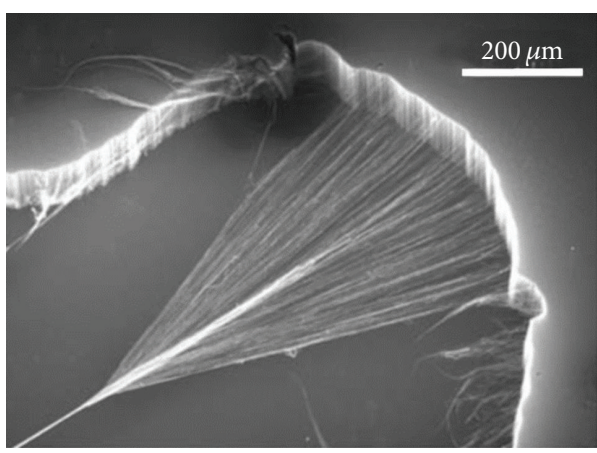

(a)

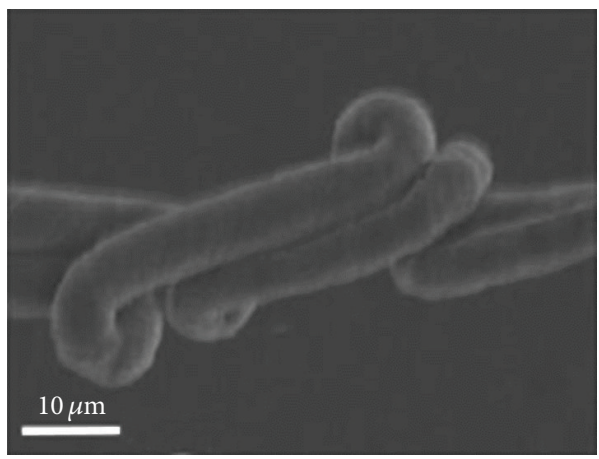

(c)

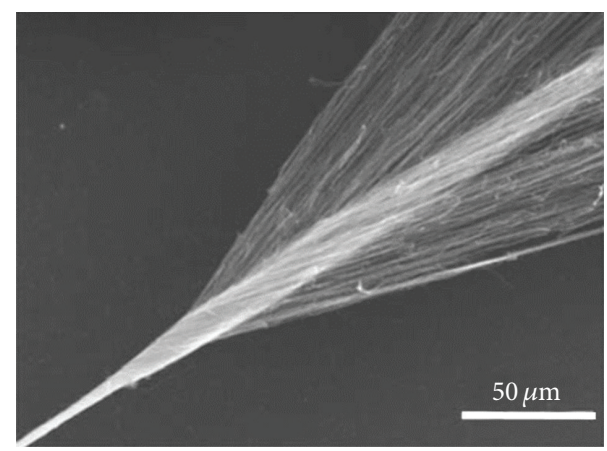

(b)

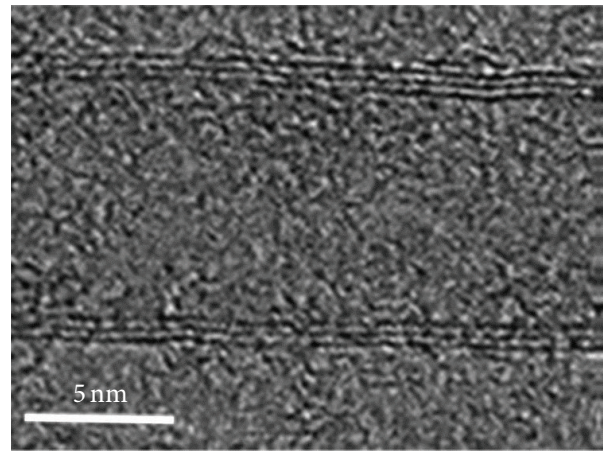

(d)

FIGURE 1: CNT fibers characterized by scanning electron microscopy (SEM) and transmission electron microscopy (TEM) [1,2]. (a) and (b) SEM images, at two different magnifications of CNT fibers in the process of being simultaneously drawn and twisted during spinning from nanotube arrays. (c) Knots could be tied in the nanotube fibers, revealing their high flexibility and resistance to torsion. (d) High-resolution TEM image of a component nanotube.

spinning from a CVD reaction zone is extendable to other types of fiber and to the spin coating of rotating objects in general. But these CNT fibers contained 5 to $10 \mathrm{wt} \%$ iron and a large number of defects. To produce desired highquality CNT fibers $[1,2]$, the high-quality nanotube arrays are firstly synthesized by a typical chemical vapor deposition method. This provided an important clue to the use of multiwalled CNTs at macroscopic scale, and researchers have made multiple efforts to optimize this aligned structure and improve the properties of CNT fibers [54-61] to many applications; for example, Chen et al. [2] and Luo et al. [3] use flexible, light-weight, ultrastrong, and semiconductive CNT fibers to develop a novel solar cell. The high alignment of building nanotubes in the fiber allows charges to separate and transport along the fibers efficiently, which provides a fiber solar cell with high performance.

In this review, we briefly highlight the fabrication of CNT fibers and its applications for solar cell, lithium ion battery, supercapacitor, and their integrated device.

\section{Fabrication of High-Quality Carbon Nanotube Fibers}

High-quality CNT fibers are obtained by dry spinning from highly aligned CNT arrays (see Figure 1). The synthetic details of the CNT arrays are summarized as follows: $\mathrm{Fe} / \mathrm{Al}_{2} \mathrm{O}_{3}$ was used as the catalyst, ethylene served as the carbon source, and $\mathrm{Ar}$ with $6 \% \mathrm{H}_{2}$ was used to carry the precursor to a tube furnace, where the growth took place. The reaction temperature was controlled at $750^{\circ} \mathrm{C}$ and the reaction time was typically between 10 and $20 \mathrm{~min}$. CNT fibers were directly spun from the high-quality aligned CNT array, and the fiber diameter was controlled from 6 to $20 \mu \mathrm{m}$ by varying the initial ribbon, a bunch of nanotubes pulled out from the array at the beginning of the spinning. The CNT fibers can be spun with lengths of tens of meters or even longer, and the fiber is uniform in diameter. The density of the nanotube fiber was calculated to be on the order of $1 \mathrm{~g} \cdot \mathrm{cm}^{-3}$, and its linear density was on the order of $10 \mu \mathrm{g} \cdot \mathrm{m}^{-1}$, relative to $10 \mathrm{mg} \cdot \mathrm{m}^{-1}$ and $20-100 \mathrm{mg} \cdot \mathrm{m}^{-1}$ for cotton and wool yarns, respectively $[1,62]$. As shown in Figure 1(c), the CNT fibers are flexible and will not break after being bent, folded, or even tied many times. High-resolution transmission electron microscopy (see Figure 1(d)) indicates a multiwalled structure for the building nanotubes with diameter of approximately $8.5 \mathrm{~nm}$ in the fiber. The high degree of alignment of the component nanotubes gives the fiber excellent mechanical and electrical properties.

\section{The Applications of Carbon Nanotube Fibers}

3.1. Dye-Sensitized Solar Cells (DSC) Based on Carbon Nanotube Fibers. A DSC, a low-cost solar cell, is based on 
a semiconductor formed between a photosensitized anode and an electrolyte, a photoelectrochemical system. The DSC can convert solar energy to electric energy, which is a promising technology to use renewable energies, and have typically been fabricated from rigid plates [63]. Solar cells are unfavorable for many applications, especially in the fields of portable and highly integrated equipment. As a result, flexible devices have become the subject of active research as a good solution [64]. In particular, weavable fiber devices are very promising and have attracted increasing attention in recent years. The CNT fibers in fiber-shaped photovoltaic devices have been widely incorporated into active layers to improve charge separation and transport or directly used as electrodes, for example, as counter electrode in replacement of conventional platinum in a planar DSC to catalyze the reduction of triiodide. For random CNT networks, the charges have to cross a lot of contacting points, so the charge transport in the random CNT networks is much slower than that in the CNT fibers. Fiber solar cells based on metal wires, glass fibers, or polymer fibers have been investigated [37-42]. Metal wires and glass fibers have bad flexibility, and conductive performance of polymer fibers is not good. So Chen et al. [2] and Luo et al. [3] developed a novel solar cell based on flexible, light-weight, ultrastrong, and semiconductive CNT fibers (Figure 2). They used CNT/N719 composite fibers to fabricate the organic solar cells on fluorine-doped tin oxide, and the power conversion efficiencies can reach $2.6 \%$; the high alignment of CNTs arrays in the fiber allows charges to separate and transport along the fibers efficiently, which provides a fiber solar cell with high performance. The efficiency of the above fiber device may be further improved through the increase of the open-circuit photovoltage value by shifting the Fermi level of nanotubes more negatively, increasing fill factor by improving the electric contact between the fiber and the charge collector and increasing the short-circuit photocurrent value by enhancing the dye loading of the nanotube fiber. This discovery expands the scope of materials and architectures available for photovoltaic devices.

To take advantage of the CNT fibers, Cai and his coauthors [5] designed and fabricated an all CNT fibers dyesensitized solar cell; CNT/N719 and CNT/PVDF fibers in Figure 3 were used as working and counter electrodes in replacement of metal wire electrode, respectively. The power conversion efficiency of this kind of photovoltaic wires was greatly improved through modification at the working electrode, for example, incorporation of titanium dioxide nanomaterials. But a short circuit was produced in this device. However, it remained challenging to obtain an ideal all CNT fibers dye-sensitized solar cell.

In order to overcome the above shortcomings, Chen et al. [8] fabricated a polymer fiber solar cell on the basis of spun CNT fibers as the electrode (Figures 4(a) and 4(b)), and the maximum energy conversion efficiency of this solar cell is only $0.15 \%$. Although the cell efficiency is low, this work provides an effective route to the development of fiber-shaped polymer solar cells. More efforts will be paid to improve the photovoltaic performance by further increasing the electrical properties of the CNT fiber and tuning the morphology and structure of the titanium dioxide

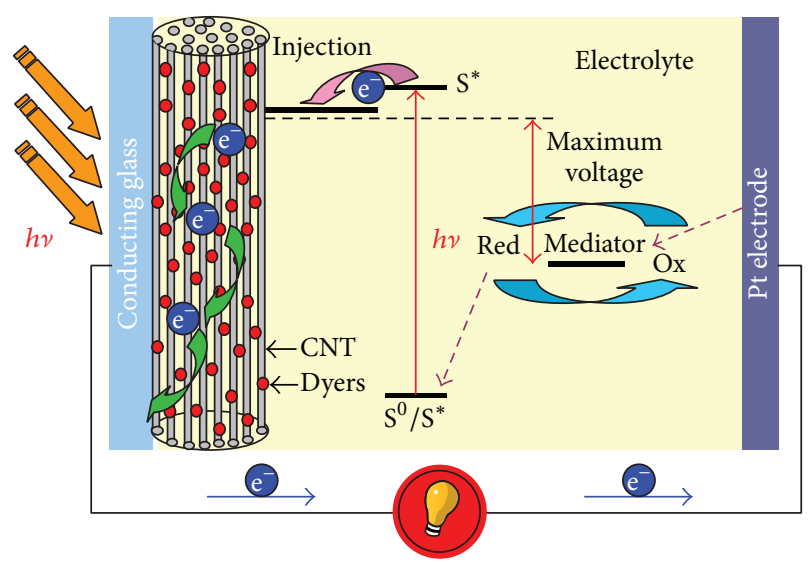

FIgURE 2: Schematic diagram of the production and transportation of photoelectron in a nanotube fiber solar cell [2].

nanotube. So the researchers [6] developed a fiber-shaped DSC based on flexible, ultralight, and ultrastrong CNT fibers as both working and counter electrodes (Figure 5), and the conversion efficiency is up to $2.94 \%$. This fiber solar cell may be easily scaled up for a practical application, as the power conversion efficiency is independent of both the cell length and the incident light. And Chen and his coauthors [9] have studied the performance of a fiber dye-sensitized solar cell by using a CNT fiber as the counter electrode and a titanium wire modified with perpendicularly aligned $\mathrm{TiO}_{2}$ nanotubes as the working electrode (Figure 4(c)). This novel interface design provides the photovoltaic wire with a high efficiency of $4.6 \%$. The photovoltaic wires can be easily integrated into various flexible devices by a convenient weaving technology, which remains challenging to conventional planar solar cells.

On this basis, Yang and his coauthors [17] have developed fiber-shaped photovoltaic devices based on graphene/Pt composite fibers (Figure 6). The high flexibility, mechanical strength, and electrical conductivity of graphene fibers resulted in a certified maximum energy conversion efficiency of $8.45 \%$, which is much higher than that of the aforementioned fiber-shaped photovoltaic devices. These flexible fiber solar cells can act as woven fabrics to make textiles by a conventional weaving technology, which enables a wide variety of applications in portable devices, for example, power regeneration for space aircraft and clothing integrated photovoltaics. These discoveries also provide a paradigm to develop new materials for high-performance solar cells.

Pan et al. [46] developed an organic thiolate/disulfide redox couple with low absorption in the visible region for use in fabricating fiber dye-sensitized solar cells (see Figure 7(a)). These flexible wire devices achieved high energy conversion efficiencies with a maximal value of $7.33 \%$. This work also opens a new avenue in the development of highly efficient optoelectronic and electronic devices by designing matchable materials in different parts and making effective structures. At the same time, a coaxial DSC fiber [14] has been fabricated with a highly aligned multiwalled CNT sheet as the counter electrode (see Figure 7(b)), and energy conversion efficiency of $4.10 \%$ is achieved. The coaxial DSC fiber also shows a 


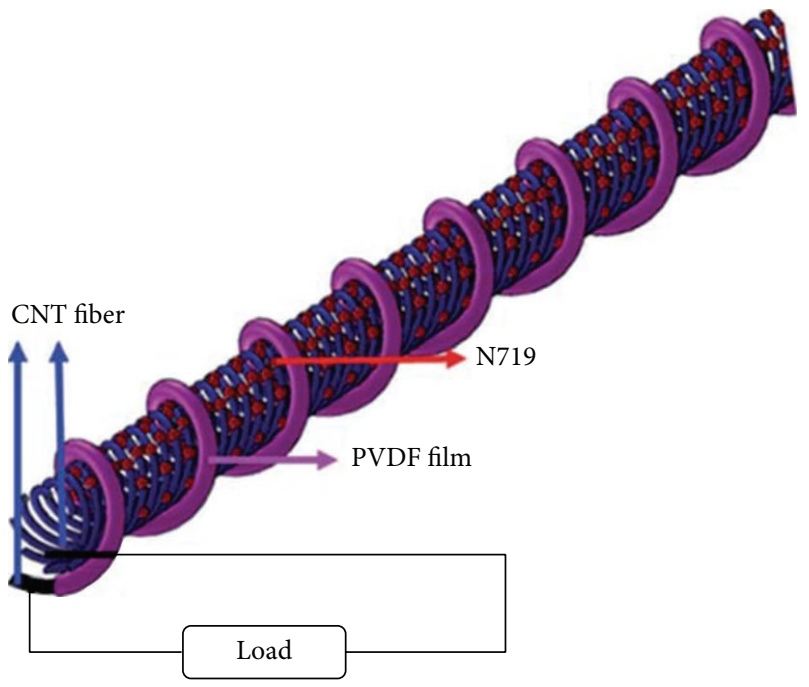

(a)

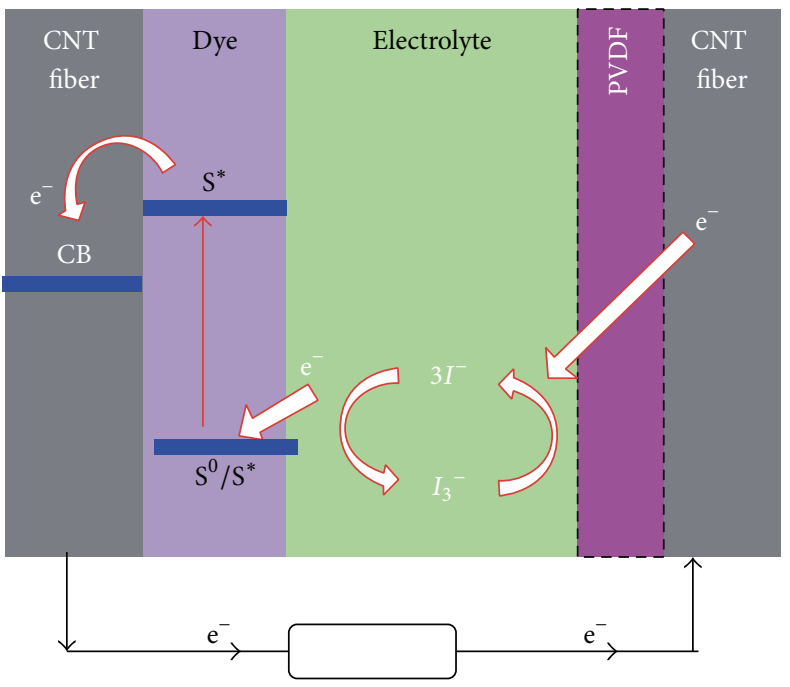

(b)

FIGURE 3: (a) Schematic illustration of a photovoltaic wire with two twined CNT fibers as working and counter electrodes, respectively. (b) The working principle of the CNT fiber-based sensitized photovoltaic wire, in which CB represents conduction band of CNT [5].

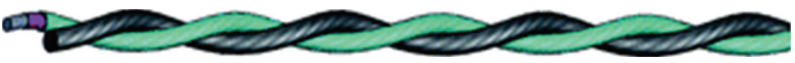

(a)

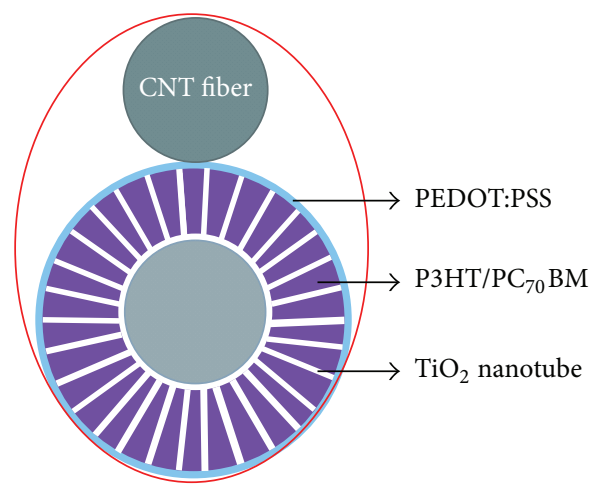

(b)

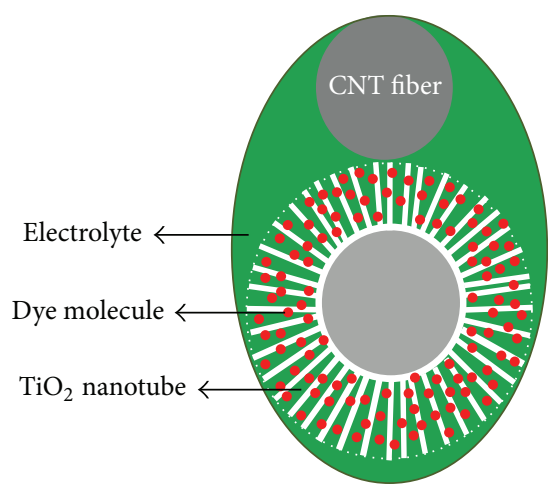

(c)

Figure 4: (a) Schematic illustration of side view of a fiber solar cell, (b) a polymer fiber solar cell from top view [8], and (c) a fiber-shaped dye-sensitized solar cell by top view [9]. Here an aligned $\mathrm{TiO}_{2}$ nanotube-modified titanium wire as the working electrode is twined with one CNT fiber as the counter electrode to produce the fiber solar cell. 


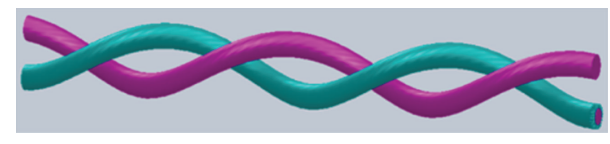

(a)

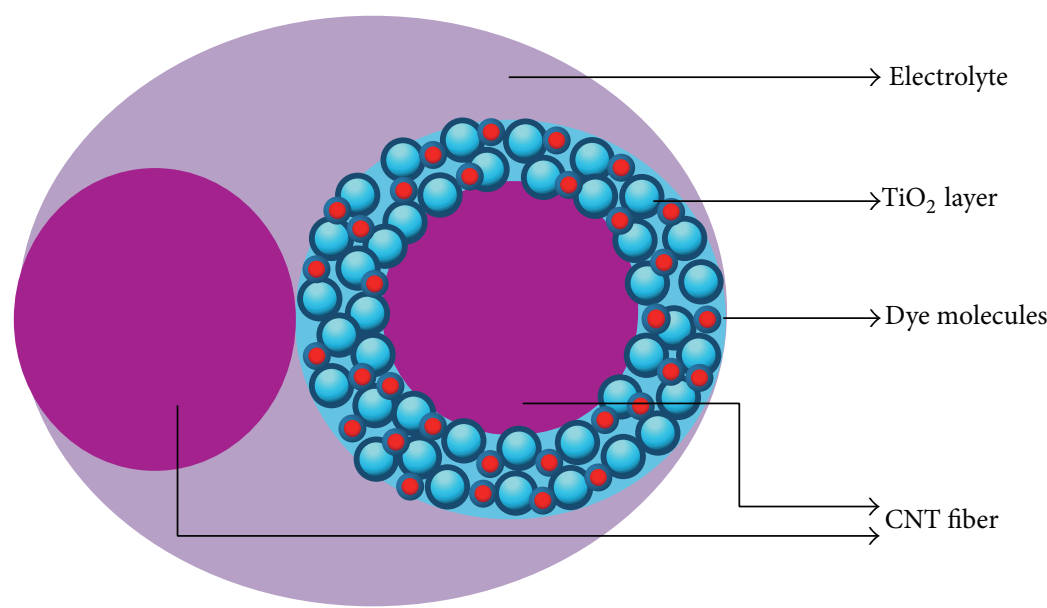

(b)

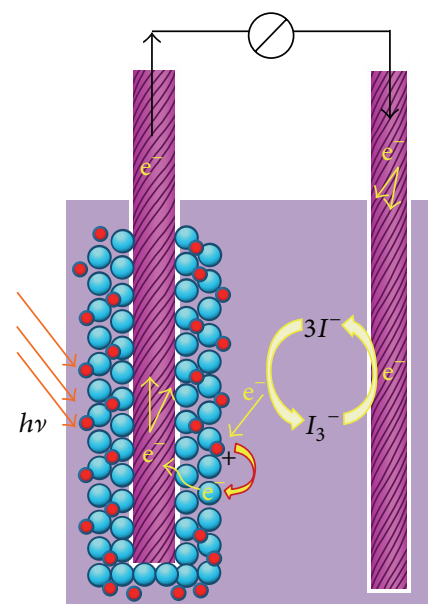

(c)

FIgURE 5: Schematic illustration of a wire-shaped DSC fabricated from two CNT fibers. (a) Two CNT fibers twined into a cell. (b) Top view of a cell. (c) Working mechanism [6].

high flexibility and stability. Although a fiber-shaped DSC has been demonstrated in this work, the aligned multiwalled CNT sheet can be also used as an electrode material to fabricate coaxial, fiber-shaped polymer solar cells and other various optoelectronic and electronic devices.

The above fiber solar cells need liquid electrolyte, which is volatile, so device performance is not stable. In order to overcome this problem, Sun et al. [19] developed a quasisolid-state, coaxial DSC fiber (see Figure 8 ), which has a high performance including a high thermal stability and flexibility that offer particularly promising applications for flexible devices at high temperatures. This fiber DSC has also established some foundations for future photovoltaics and electronics with an ongoing push towards smaller and faster devices that are still confined to the planar silicon wafer.

\subsection{Supercapacitor Based on Carbon Nanotube Fibers. Super-} capacitor, formerly electric double-layer capacitor or pseudocapacitor, is one important electrochemical energy storage device that has been extensively developed for many applications. The energy storage capability, power delivery capability, and cycle life of supercapacitor are highly desired to satisfy the increasing performance demands. CNT fibers have been explored as both electrode materials and electrode additives for developing high-performance supercapacitors which based on CNT fibers recently attracted more attention. Cai et al. [24] synthesized highly aligned multiwalled CNT-polyaniline composite fibers with excellent mechanical, electrical, and electrochemical properties through an easy electrodeposition process. They were further twisted to fabricate a fiber-shaped supercapacitor (see Figure 9) with high specific capacitances up to $263 \mathrm{mF} \mathrm{cm}^{-1}$. The light weight, high flexibility, high strength, and good weavability provide them with promising applications in various fields. This work also presents a fabrication paradigm for the development of high performance energy storage devices based on the use of new electrode nanomaterials. A flexible and wearable electric double-layer capacitor wire by twisting two aligned multiwalled CNT/ordered mesoporous carbon composite fibers as electrodes has been developed. 


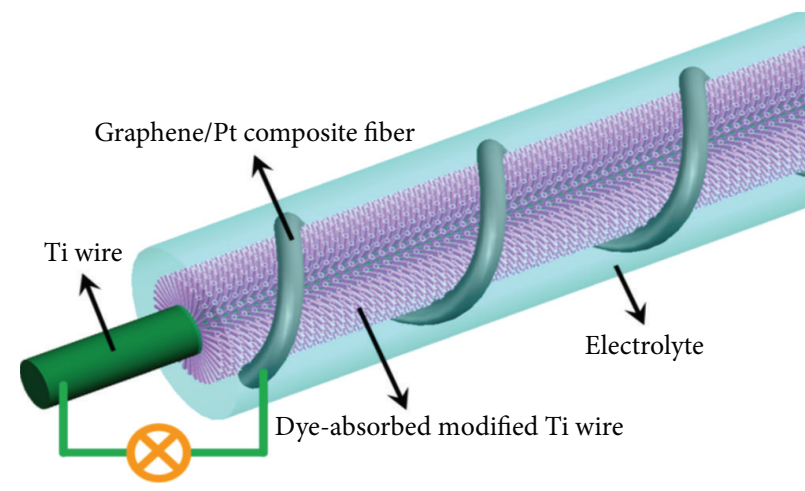

(a)

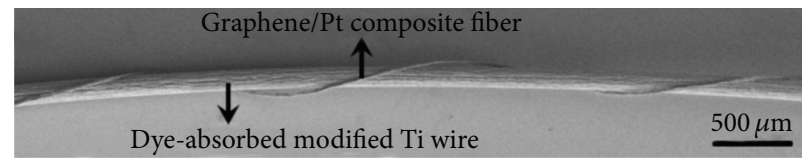

(b)

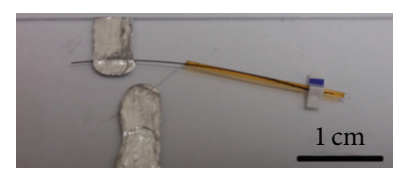

(c)

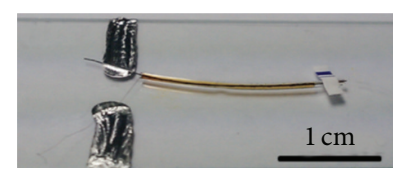

(d)

Figure 6: Dye-sensitized photovoltaic wire prepared by using a graphene/Pt composite fiber as the counter electrode and a Ti wire impregnated with $\mathrm{TiO}_{2}$ nanotubes as the working electrode. (a) Schematic illustration. (b) SEM image. (c) and (d) Photographs of photovoltaic wires sealed in a capillary glass tube and flexible fluorinated ethylene propylene tube, respectively [17].

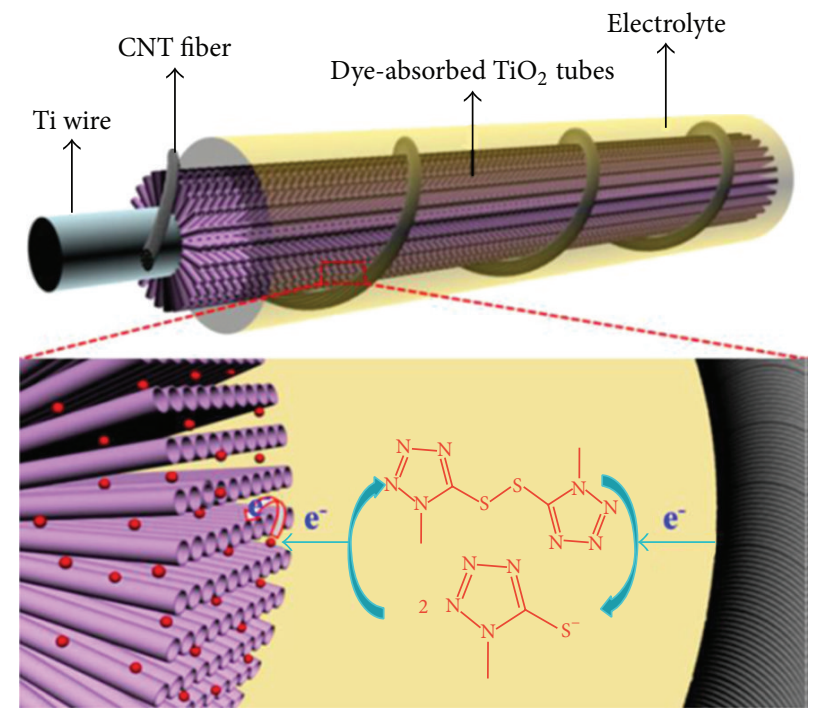

(a)

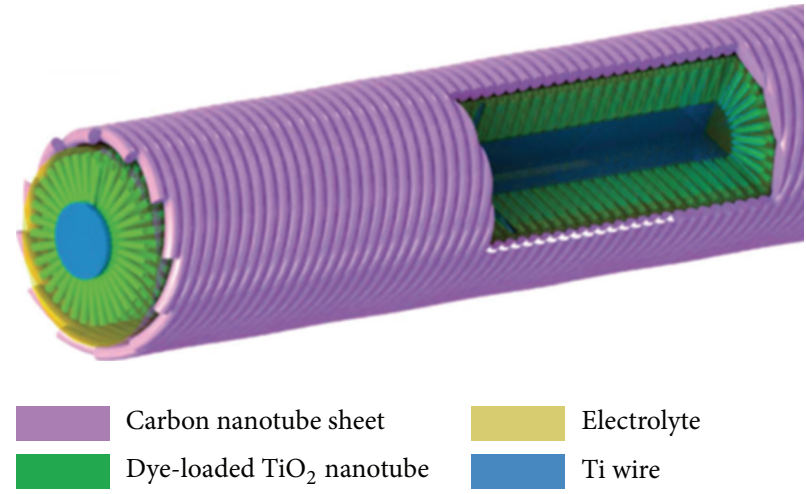

(b)

Figure 7: (a) Schematic illustration of a photovoltaic wire with a CNT fiber as the counter electrode, a Ti wire impregnated with titania nanotubes as the working electrode, and the thiolate/disulfide redox couple as the electrolyte [46]. (b) Schematic illustration of the coaxial DSC fiber [14].

As the ordered mesoporous carbon is incorporated into the axially aligned multiwalled CNT skeleton to combine the structure and property advantages of the two components in the composite fiber electrode, the electric double-layer capacitor wire exhibits high specific capacitance and long life stability. Compared with the conventional planar structure, the capacitor wire is also lightweight and can be integrated into various textile structures that are particularly promising for portable and wearable electronic devices.
And then Chen et al. [25] developed coaxial electric double-layer capacitor fibers from the CNT fibers (see Figure 10), which functioned as two electrodes with a polymer gel sandwiched between them. The unique coaxial structure had decreased the contact resistance between the two electrodes with a maximum discharge capacitance of $59 \mathrm{~F} \mathrm{~g}^{-1}\left(32.09 \mathrm{~F} \mathrm{~cm}^{-3}\right.$ or $29 \mu \mathrm{F} \mathrm{cm}^{-1}$ or $\left.8.66 \mathrm{mF} \mathrm{cm}^{-2}\right)$, much higher than $4.5 \mathrm{~F} \mathrm{~g}^{-1}$ of the electric double-layer capacitor by twisting two CNT fibers together. These electric double-layer 


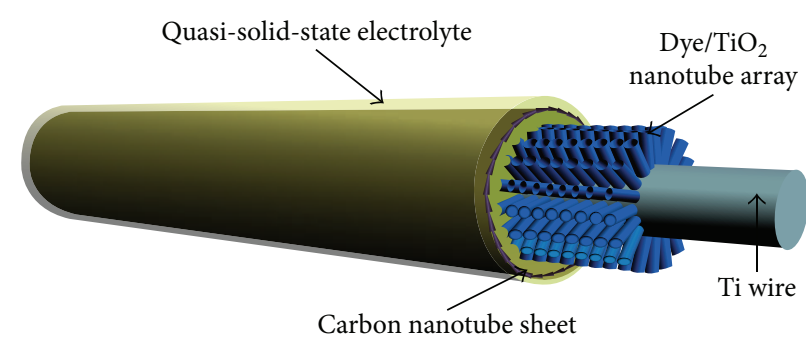

(a)

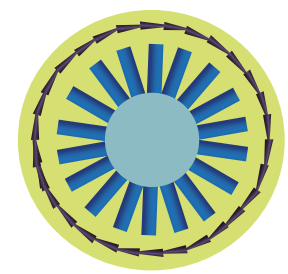

(b)

FIGURE 8: Schematic illustration of the quasi-solid-state, coaxial, fiber-shaped DSC. (a) Side view. (b) Cross-sectional view [19].

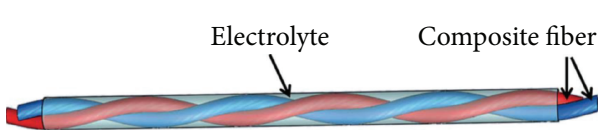

(a)

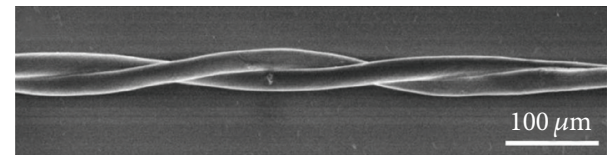

(b)

FIGURE 9: Two aligned multiwalled CNT-polyaniline composite fibers twisted into a supercapacitor wire. (a) Schematic illustration. (b) Typical scanning electron microscopy image [24, 28].

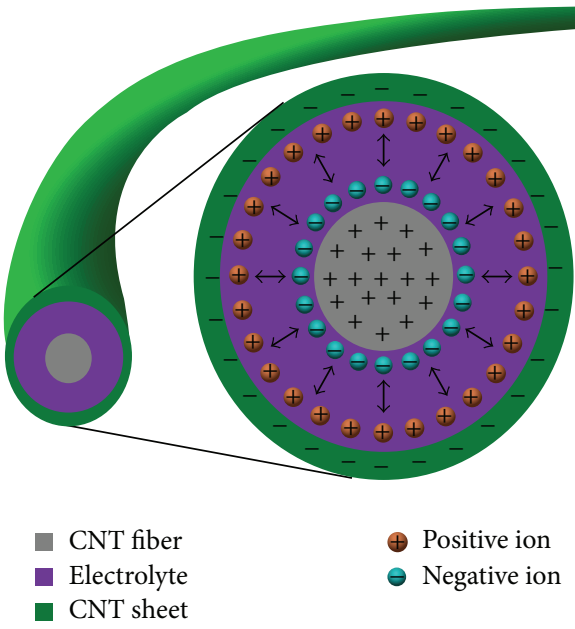

(a)
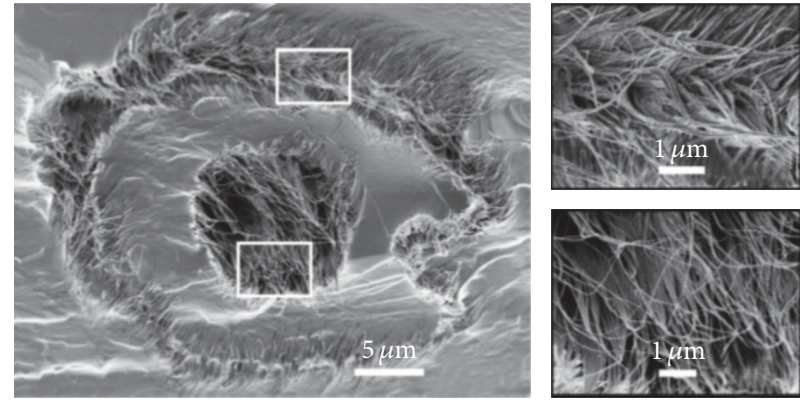

(b)

FIGURE 10: Schematic illustration to both the cross-sectional structure and mechanism for the high electrochemical property of the coaxial electric double-layer capacitor fiber. (a) The electropositive CNT fiber and electronegative CNT sheet functioned as the positive and negative electrodes, respectively; (b) SEM images at low (left image) and high (right images) magnifications for a cross section. The right images correspond to the left rectangle-labeled areas [25].

capacitor fibers exhibit energy densities up to $1.88 \mathrm{Wh} \mathrm{kg}^{-1}$ and power densities up to $755.9 \mathrm{~W} \mathrm{~kg}^{-1}$. In addition, they are flexible and stretchable and can be easily scaled up with high efficiency and low cost. These electric double-layer capacitor fibers also represent the first demonstration of stretchable energy devices in a fiber format, which is critically important for the practical application in the flexible equipment such as various electronic textiles. This work further provides a general and effective strategy in the development of highly efficient electronic devices.

Yang et al. [47] and Xu et al. [65] developed highly stretchable, fiber-shaped, high-performance supercapacitors (see Figure 11). Aligned CNT sheets that are sequentially wrapped on an elastic fiber serve as two electrodes (see Figure 11(a)). The use of aligned CNT sheets offers combined remarkable properties including high flexibility, tensile strength, electrical conductivity, and mechanical and thermal stability. As a result, the fiber-shaped supercapacitor maintains a high specific capacitance of approximately $18 \mathrm{~F} / \mathrm{g}$ after stretch by $75 \%$ for 100 cycles. The high stretchability and specific capacitance have been simultaneously achieved by designing a coaxial structure that favors high contact areas between the electrode and electrolyte besides the combined remarkable properties enabled by the aligned CNTs. 


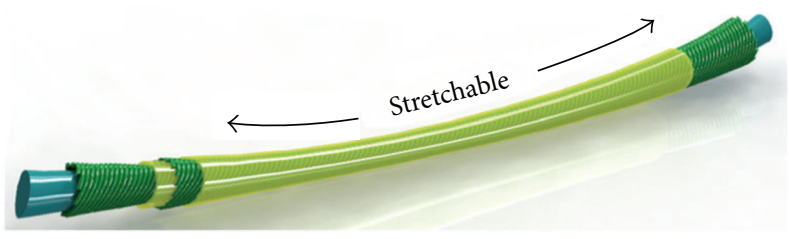

(a)

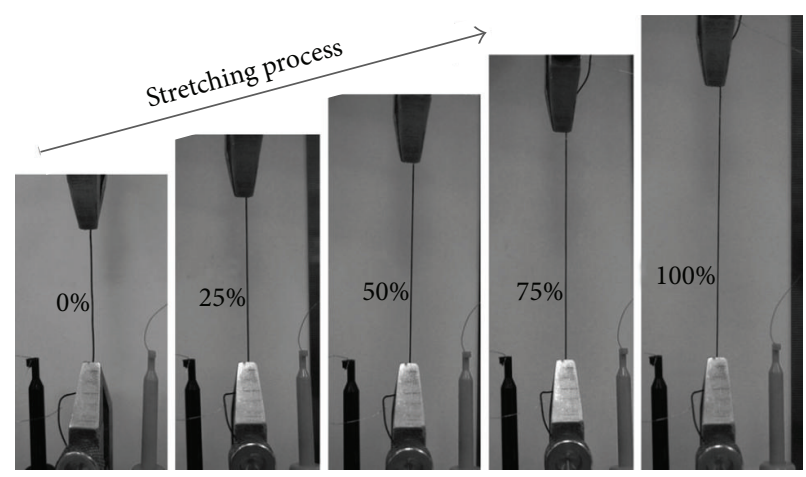

(b)

FIGURE 11: (a) A highly stretchable, fiber-shaped supercapacitor with a coaxial structure. (b) Photograph of the fiber-shaped supercapacitor with different strains of $0 \%, 25 \%, 50 \%, 75 \%$, and $100 \%$ [47].

\subsection{Lithium Ion Battery Based on Carbon Nanotube Fibers.} Lithium ion batteries are receiving considerable attention in applications, ranging from portable electronics to electric vehicles, due to their superior energy density over other rechargeable battery technologies. However, lighter, thinner, and higher capacity lithium ion batteries necessitate ongoing research for novel materials with improved properties. Researchers require a concerted development of both electrodes and electrolyte to improve battery capacity, cycle life, and charge-discharge rates while maintaining the highest degree of safety available. CNT fibers are a candidate material for use in lithium ion batteries. A fiber device can be easily woven into textiles or other structures to exhibit unique and promising applications. CNT fibers as a conductive additive at a lower weight loading than conventional carbons, like carbon black and graphite, present a more effective strategy to establish an electrical percolation network. Ren et al. [22] used twisted CNT fibers and composite fibers to produce both fiber-shaped lithium ion batteries with high capacitive performances (see Figure 12). The microsupercapacitor fiber was fabricated by twisting two CNT fibers and showed a mass specific capacitance of $13.31 \mathrm{~F} / \mathrm{g}$, area specific capacitance of $3.01 \mathrm{mF} / \mathrm{cm}^{2}$, or length specific capacitance of $0.015 \mathrm{mF} / \mathrm{cm}$ at $2 \times 10^{-3} \mathrm{~mA}(1.67 \mathrm{~A} / \mathrm{g})$. The fiber-shaped battery was produced by twisting a CNT fiber and a lithium wire which functioned as positive and negative electrodes, respectively. The specific capacity was calculated as $94.37 \mathrm{mAh} / \mathrm{cm}^{3}$ or $174.40 \mathrm{mAh} / \mathrm{g}$ at $2 \times 10^{-3} \mathrm{~mA}$. The energy and power densities in both supercapacitors and batteries could be further greatly improved by incorporation of $\mathrm{MnO}_{2}$ nanoparticles into CNT fibers. For instance, the charge and discharge energy densities achieved 92.84 and $35.74 \mathrm{mWh} / \mathrm{cm}^{3}$ while the charge and discharge power densities were 3.87 and $2.43 \mathrm{~W} / \mathrm{cm}^{3}$ at $2 \times$ $10^{-3} \mathrm{~mA}$ in the fiber-shaped microbattery. The combined flexible fiber structure and high tensile strength also enable promising applications in various fields; for example, these fibers can be easily integrated into electronic textiles by a conventional weaving technique. This work further presented a fabrication paradigm in the development of novel storage devices by using strong and conductive nanostructured fibers as effective electrodes.

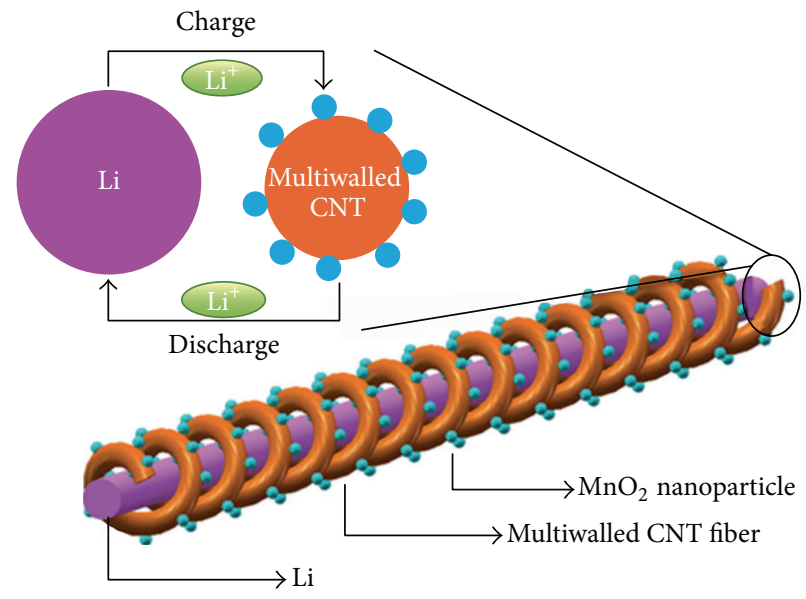

FIGURE 12: Fiber-shaped lithium ion battery fabricated by twisting an aligned multiwalled $\mathrm{CNTs} / \mathrm{MnO}_{2}$ composite fiber and $\mathrm{Li}$ wire as positive and negative electrodes, respectively. The inserted top left image shows the charge-discharge process [22].

And then Lin et al. [23] reported the development of twisted, aligned multi-walled CNT/Si composite fiber anodes for flexible, fiber-shaped lithium ion batteries (Figure 13). A thin layer of silicon was coated on the outer surface of the aligned multiwalled CNTs to form a core-sheath structure that can effectively and simultaneously exploit the high specific capacity of the silicon and high electrical conductivity of the multiwalled CNTs, while the designed space with sizes of tens to hundreds of nanometers among the aligned composite nanotubes can effectively counterbalance the volume change of the silicon component. As a result, the aligned multiwalled $\mathrm{CNTs} / \mathrm{Si}$ fiber electrode shows a combined high specific capacity and cyclic stability. And this fiber electrode offers unique advantages, such as being lightweight and weavable compared with the conventional planar structure. This core-sheath architecture and aligned structure of the multiwalled CNTs/Si composite nanotubes display a remarkable electrochemical performance, including high specific capacity and cyclic stability. 


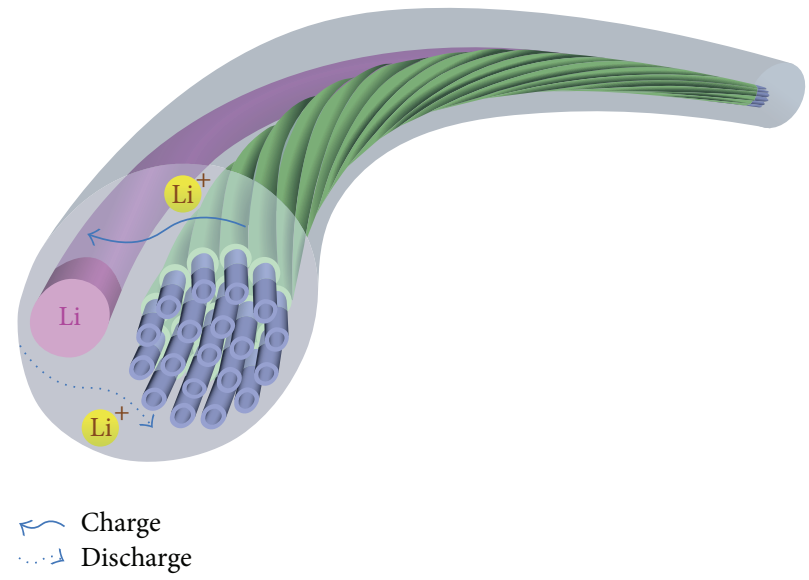

FIGURE 13: Schematic illustration of a half lithium-ion battery based on the aligned multiwalled CNT/Si composite fiber as a working electrode with a lithium wire as both counter and reference electrodes [23].

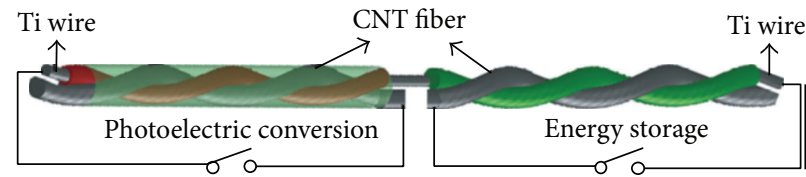

(a)

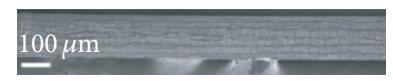

(b)

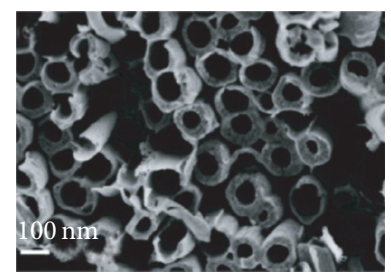

(c)

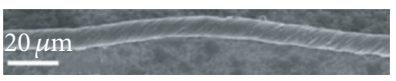

(d)

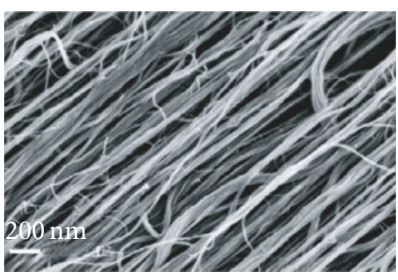

(e)

FIgURE 14: (a) The integrated wire-shaped device for photoelectric conversion and energy storage. (b), (c) Scanning electron microscopy images of aligned titania nanotubes grown on a Ti wire by electrochemical anodization for $2 \mathrm{~h}$ at low and high magnifications, respectively. (d) and (e) SEM images of a CNT fiber at low and high magnifications, respectively [48].

3.4. The Integrated Wire-Shaped Device Based on Carbon Nanotube Fibers. The solar energy is converted into electric energy which is transferred through external electric wires to electrochemical devices, such as lithium ion batteries and supercapacitors. To further improve the energy conversion and storage efficiency, it is important to simultaneously realize the two functions, photoelectric conversion (PC) and energy storage (ES), in one device. Recently, attempts have been made to directly stack a photovoltaic cell and a supercapacitor into one device which can absorb and store solar energy. Chen et al. [48] developed an integrated energy fiber to simultaneously realize PC and ES with high efficiency (see Figure 14). A titanium wire was modified in sections with aligned titania nanotubes on the surface. Active materials for PC and ES were then coated onto the modified parts within titania nanotubes. CNT fibers were twisted with the modified Ti wire to produce the desired device. The Ti wire and CNT fiber had been used as electrodes. Figure 14(a) schematically shows a wire in which one part is capable of PC and one part is capable of ES. This integrated fiber device exhibits an overall photoelectric conversion and storage efficiency of $1.5 \%$. The fiber structure also enables unique and promising applications; for example, it is envisaged that it can be easily integrated into electronic textiles by a well-defined weaving technique and serve as a self-powering system for portable microelectronic devices and equipment.

Zhang et al. [33] have developed an all solid-state, coaxial, and self-powered "energy fiber" which simultaneously converts solar energy to electric energy and stores it (Figure 15). The design of a coaxial structure in the "energy fiber" enables promising advantages for both PC and ES. For the PC part, it is similar to the efficient planar polymer solar cell in the radial direction, so the generated charges can be rapidly separated and transported to produce high photocurrents. For the ES 


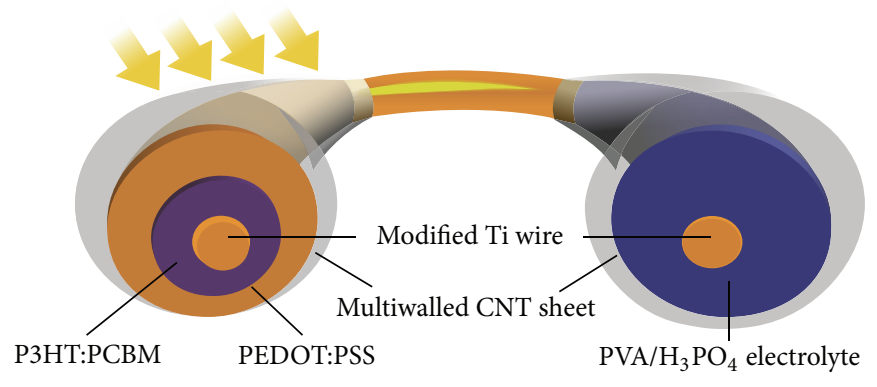

(a)

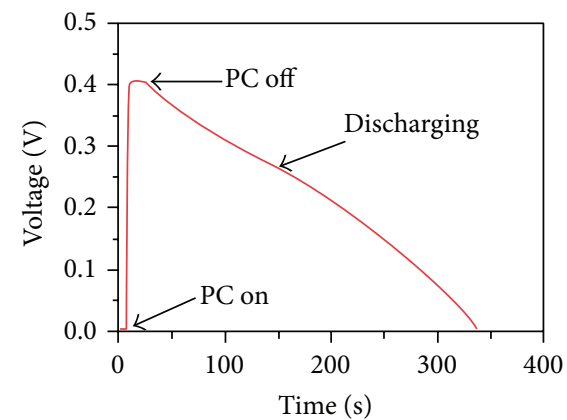

(c)

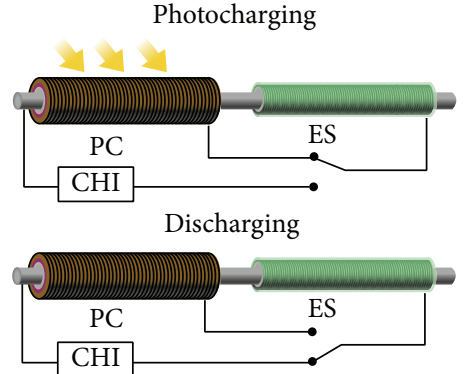

(b)
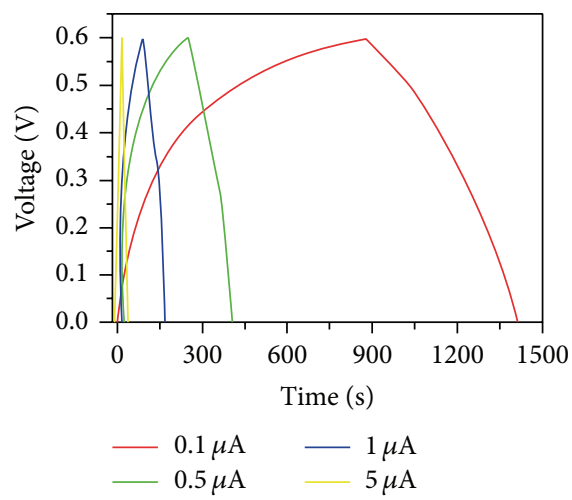

(d)

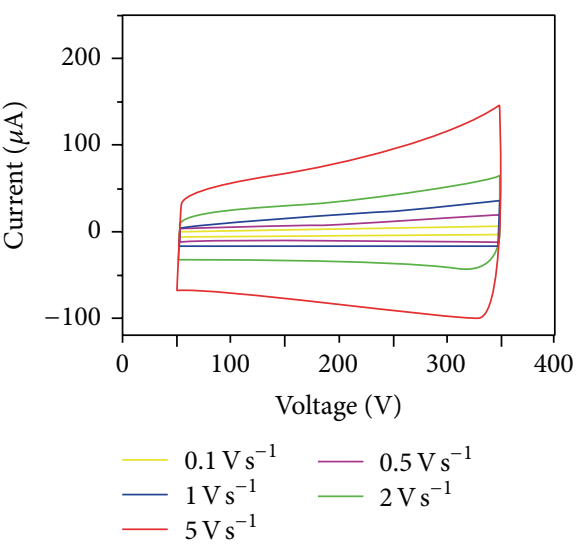

(e)

Figure 15: (a) Schematic illustration to the structure of all-solid-state, coaxial, and integrated fiber device. The left and right sections correspond to the PC and ES parts, respectively. (b) Schematic diagram shows the circuit connection state in the process of charging and discharging. (c) Charging-discharging curve with a current of $0.1 \mu \mathrm{A}$ during the discharging process. (d) Galvanostatic charging-discharging curve of the self-charging fiber at different current from $0.1,0.5$, and 1 to $5 \mu \mathrm{A}$. (e) Cyclic voltammograms at increasing scan rates from 0.1 to $5 \mathrm{~V} \mathrm{~s}^{-1}[33]$.

part, different from the explored twisted structure of two fiber electrodes with high electrical resistances, the coaxial structure with much higher effective contact area also favors a rapid charge transport. In addition, the use of flexible, transparent, strong, and conductive multiwalled CNT sheets can also greatly improve the photoelectric conversion and energy storage. The "energy fiber" is flexible and can be scaled up for the practical application by the well-developed textile technology and may open a new avenue to future photoelectronics and electronics.
And then Chen et al. [49] have developed an energy fiber which can simultaneously realize energy conversion and storage by integrating dye-sensitized solar cell and electrochemical capacitor (see Figure 16). A Ti wire substrate modified with perpendicularly aligned titania nanotubes on the surface and horizontally aligned CNT sheets serves as two electrodes in the integrated "energy fiber" device. The maximal photoelectric conversion efficiency achieved $2.73 \%$, while the energy storage efficiency reached $75.7 \%$ with specific capacitances up to $0.156 \mathrm{mFcm}^{-1}$ or $3.32 \mathrm{mFcm}^{-2}$ and 


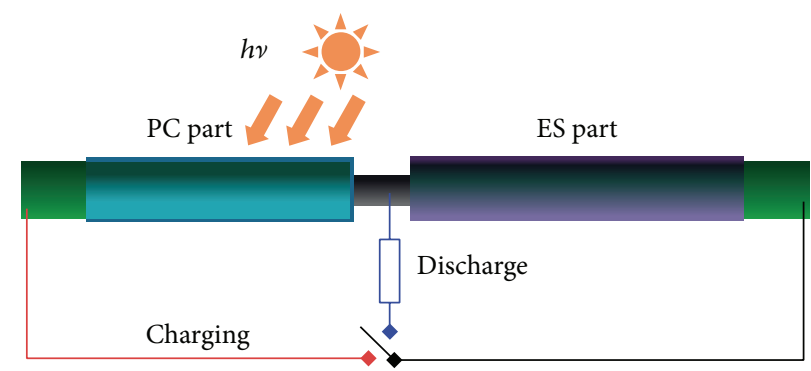

(a)

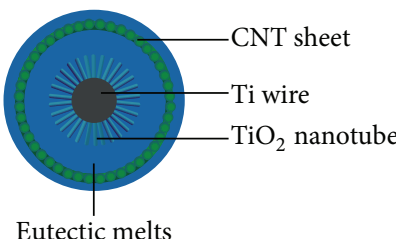

(b)

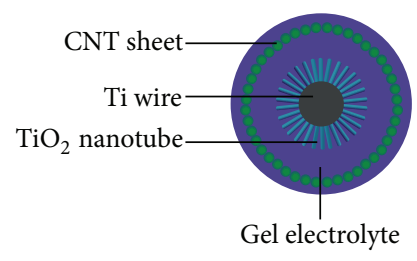

(c)

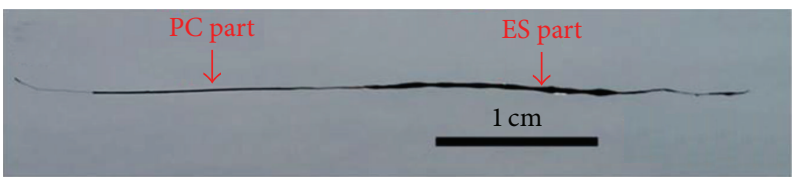

(d)

Figure 16: (a) Schematic illustration of the structure of the coaxially integrated dye-sensitized solar cell and electrochemical capacitor into an "energy fiber." (b) and (c) Cross-sectional views of the PC and ES parts of the "energy fiber," respectively. (d) Photograph of an "energy fiber" [49].

power densities up to $0.013 \mathrm{~mW} \mathrm{~cm}^{-1}$ or $0.27 \mathrm{~mW} \mathrm{~cm}^{-2}$ at a current of $50 \mathrm{~mA}$. The "energy fiber" is flexible and stable and shows promising applications for various portable electronic devices that require lightweight and weavable materials.

\section{Conclusions}

The recent studies of the CNT fibers for optoelectric conversion and energy storage are summarized. The CNT has been extensively applied to fiber-shaped dye-sensitized solar cell, lithium ion battery, supercapacitor, and their integrated device. These "energy fibers" are flexible, stable, and stretchable and show promising applications to be integrated into electronic textiles by a well-defined weaving technique and serve as a self-powering system for portable microelectronic devices and equipment.

\section{Conflict of Interests}

The authors declare that there is no conflict of interests regarding the publication of this paper.

\section{Acknowledgments}

The authors thank the support of the New-Century Training Program Foundation for the Talents by the Ministry of
Education of China (NCET-11-0979) and Introducing Highlevel Talent Research Start Fund of Central South University of Forestry and Technology (no. 1040281).

\section{References}

[1] M. Zhang, K. R. Atkinson, and R. H. Baughman, "Multifunctional carbon nanotube yarns by downsizing an ancient technology," Science, vol. 306, no. 5700, pp. 1358-1361, 2004.

[2] T. Chen, S. T. Wang, Z. B. Yang et al., "Flexible, light-weight, ultrastrong, and semiconductive carbon nanotube fibers for a highly efficient solar cell," Angewandte Chemie: International Edition, vol. 50, no. 8, pp. 1815-1819, 2011.

[3] Y. F. Luo, Z. Q. Gong, M. D. He, X. J. Wang, Z. H. Tang, and H. Chen, "Fabrication of high-quality carbon nanotube fibers for optoelectronic applications," Solar Energy Materials and Solar Cells, vol. 97, pp. 78-82, 2012.

[4] Z. Yang, T. Chen, R. He et al., "Aligned carbon nanotube sheets for the electrodes of organic solar cells," Advanced Materials, vol. 23, no. 45, pp. 5436-5439, 2011.

[5] F. Cai, T. Chen, and H. Peng, "All carbon nanotube fiber electrode-based dye-sensitized photovoltaic wire," Journal of Materials Chemistry, vol. 22, no. 30, pp. 14856-14860, 2012.

[6] T. Chen, L. Qiu, Z. Cai et al., "Intertwined aligned carbon nanotube fiber based dye-sensitized solar cells," Nano Letters, vol. 12, no. 5, pp. 2568-2572, 2012.

[7] T. Chen, L. Qiu, H. G. Kia, Z. Yang, and H. Peng, "Designing aligned inorganic nanotubes at the electrode interface: towards highly efficient photovoltaic wires," Advanced Materials, vol. 24, no. 34, pp. 4623-4628, 2012. 
[8] T. Chen, L. Qiu, H. Li, and H. Peng, "Polymer photovoltaic wires based on aligned carbon nanotube fibers," Journal of Materials Chemistry, vol. 22, no. 44, pp. 23655-23658, 2012.

[9] T. Chen, L. B. Qiu, H. G. Kia, Z. B. Yang, and H. S. Peng, "Designing aligned inorganic nanotubes at the electrode interface: towards highly efficient photovoltaic wires," Advanced Materials, vol. 24, no. 34, pp. 4623-4628, 2012.

[10] S. Q. Huang, Z. B. Yang, L. L. Zhang et al., "A novel fabrication of a well distributed and aligned carbon nanotube film electrode for dye-sensitized solar cells," Journal of Materials Chemistry, vol. 22, no. 33, pp. 16833-16838, 2012.

[11] Z. Yang, L. Li, H. Lin et al., "Penetrated and aligned carbon nanotubes for counter electrodes of highly efficient dye-sensitized solar cells," Chemical Physics Letters, vol. 549, pp. 82-85, 2012.

[12] X. Fang, Z. Yang, L. Qiu et al., "Core-sheath carbon nanostructured fibers for efficient wire-shaped dye-sensitized solar cells," Advanced Materials, vol. 26, no. 11, pp. 1694-1698, 2013.

[13] G. Guan, Z. Yang, L. Qiu et al., "Oriented PEDOT:PSS on aligned carbon nanotubes for efficient dye-sensitized solar cells," Journal of Materials Chemistry A, vol. 1, no. 42, pp. 1326813273, 2013.

[14] H. Sun, X. You, Z. Yang, J. Deng, and H. Peng, "Winding ultrathin, transparent, and electrically conductive carbon nanotube sheets into high-performance fiber-shaped dye-sensitized solar cells," Journal of Materials Chemistry A, vol. 1, no. 40, pp. 1242212425, 2013.

[15] Z. Yang, T. Chen, R. He et al., "A novel carbon nanotube/polymer composite film for counter electrodes of dye-sensitized solar cells," Polymer Chemistry, vol. 4, no. 5, pp. 1680-1684, 2013.

[16] Z. Yang, M. Liu, C. Zhang, W. W. Tjiu, T. Liu, and H. Peng, "Carbon nanotubes bridged with graphene nanoribbons and their use in high-efficiency dye-sensitized solar cells," Angewandte Chemie-International Edition, vol. 52, no. 14, pp. 3996-3999, 2013.

[17] Z. Yang, H. Sun, T. Chen, L. Qiu, Y. Luo, and H. Peng, "Photovoltaic wire derived from a graphene composite fiber achieving an $8.45 \%$ energy conversion efficiency," Angewandte ChemieInternational Edition, vol. 52, no. 29, pp. 7545-7548, 2013.

[18] H. Li, Z. Yang, L. Qiu et al., "Stable wire-shaped dye-sensitized solar cells based on eutectic melts," Journal of Materials Chemistry A, vol. 2, no. 11, pp. 3841-3846, 2014.

[19] H. Sun, H. Li, X. You et al., "Quasi-solid-state, coaxial, fibershaped dye-sensitized solar cells," Journal of Materials Chemistry A, vol. 2, no. 2, pp. 345-349, 2014.

[20] H. Sun, Z. Yang, X. Chen et al., "Photovoltaic wire with high efficiency attached onto and detached from a substrate using a magnetic field," Angewandte Chemie, vol. 52, no. 32, pp. 82768280, 2013.

[21] X. Fang, Z. Yang, L. Qiu et al., "Core-sheath carbon nanostructured fibers for efficient wire-shaped dye-sensitized solar cells," Advanced Materials, vol. 26, no. 11, pp. 1694-1698, 2014.

[22] J. Ren, L. Li, C. Chen et al., "Twisting carbon nanotube fibers for both wire-shaped micro-supercapacitor and micro-battery," Advanced Materials, vol. 25, no. 8, pp. 1155-1159, 2013.

[23] H. Lin, W. Weng, J. Ren et al., "Twisted aligned carbon nanotube/silicon composite fiber anode for flexible wire-shaped lithium-ion battery," Advanced Materials, vol. 26, no. 8, pp.12171222, 2014.

[24] Z. Cai, L. Li, J. Ren, L. Qiu, H. Lin, and H. Peng, "Flexible, weavable and efficient microsupercapacitor wires based on polyaniline composite fibers incorporated with aligned carbon nanotubes," Journal of Materials Chemistry A, vol. 1, no. 2, pp. 258-261, 2013.

[25] X. Chen, L. Qiu, J. Ren et al., "Novel electric double-layer capacitor with a coaxial fiber structure," Advanced Materials, vol. 25, no. 44, pp. 6436-6441, 2013.

[26] H. Lin, L. Li, J. Ren et al., "Conducting polymer composite film incorporated with aligned carbon nanotubes for transparent, flexible and efficient supercapacitor," Scientific Reports, vol. 3, article 1353, 2013.

[27] M. K. Liu, Y. E. Miao, C. Zhang et al., "Hierarchical composites of polyaniline-graphene nanoribbons-carbon nanotubes as electrode materials in all-solid-state supercapacitors," Nanoscale, vol. 5, no. 16, pp. 7312-7320, 2013.

[28] J. Ren, W. Bai, G. Guan, Y. Zhang, and H. Peng, "Flexible and weaveable capacitor wire based on a carbon nanocomposite fiber," Advanced Materials, vol. 25, no. 41, pp. 5965-5970, 2013.

[29] Z. Yang, J. Deng, X. Chen, J. Ren, and H. Peng, "A highly stretchable, fiber-shaped supercapacitor," Angewandte Chemie International Edition, vol. 52, no. 50, pp. 13453-13457, 2013.

[30] L. Li, Z. Yang, H. J. Gao et al., "Vertically aligned and penetrated carbon nanotube/polymer composite film and promising electronic applications," Advanced Materials, vol. 23, no. 32, pp. 3730-3735, 2011.

[31] T. Chen, L. Qiu, Z. Yang et al., "An integrated "energy wire" for both photoelectric conversion and energy storage," Angewandte Chemie-International Edition, vol. 51, no. 48, pp. 11977-11980, 2012.

[32] Z. Yang, L. Li, Y. Luo et al., "An integrated device for both photoelectric conversion and energy storage based on freestanding and aligned carbon nanotube film," Journal of Materials Chemistry A, vol. 1, no. 3, pp. 954-958, 2013.

[33] Z. Zhang, X. Chen, P. Chen et al., "Integrated polymer solar cell and electrochemical supercapacitor in a flexible and stable fiber format," Advanced Materials, vol. 26, no. 3, pp. 466-470, 2014.

[34] X. Chen, H. Sun, Z. Yang et al., "A novel "energy fiber" by coaxially integrating dye-sensitized solar cell and electrochemical capacitor," Journal of Materials Chemistry A, vol. 2, no. 6, pp. 1897-1902, 2014.

[35] H. Sun, X. You, J. Deng et al., "Novel graphene/carbon nanotube composite fibers for efficient wire-shaped miniature energy devices," Advanced Materials, vol. 26, no. 18, pp. 2868-2873, 2014.

[36] Y. Luo, L. Li, S. Huang, T. Chen, and H. Luo, "Functional nanomaterials for optoelectric conversion and energy storage," Journal of Nanomaterials, vol. 2013, Article ID 414193, 2 pages, 2013.

[37] J. Liu, M. A. Namboothiry, and D. L. Carroll, "Optical geometries for fiber-based organic photovoltaics," Applied Physics Letters, vol. 90, no. 13, Article ID 133515, 2007.

[38] J. Ramier, C. J. G. Plummer, Y. Leterrier, J.-. E. Månson, B. Eckert, and R. Gaudiana, "Mechanical integrity of dye-sensitized photovoltaic fibers," Renewable Energy, vol. 33, no. 2, pp. 314-319, 2008.

[39] B. O'Connor, K. P. Pipe, and M. Shtein, "Fiber based organic photovoltaic devices," Applied Physics Letters, vol. 92, no. 19, Article ID 193306, 2008.

[40] X. Fan, Z. Chu, F. Wang et al., "Wire-shaped flexible dyesensitized solar cells," Advanced Materials, vol. 20, no. 3, pp. 592-595, 2008.

[41] B. Weintraub, Y. Wei, and Z. L. Wang, "Optical fiber/nanowire hybrid structures for efficient three-dimensional dye-sensitized 
solar cells," Angewandte Chemie - International Edition, vol. 48, no. 47, pp. 8981-8985, 2009.

[42] M. R. Lee, R. D. Eckert, K. Forberich, G. Dennler, C. J. Brabec, and R. A. Gaudiana, "Solar power wires based on organic photovoltaic materials," Science, vol. 324, no. 5924, pp. 232-235, 2009.

[43] Q. Li, Y. Li, X. Zhang et al., "Structure-dependent electrical properties of carbon nanotube fibers," Advanced Materials, vol. 19, no. 20, pp. 3358-3363, 2007.

[44] C. Yen, Y. Lin, S. Liao et al., "Preparation and properties of a carbon nanotube-based nanocomposite photoanode for dyesensitized solar cells," Nanotechnology, vol. 19, no. 37, Article ID 375305, 2008.

[45] S. Berson, R. de Bettignies, S. Bailly, S. Guillerez, and B. Jousselme, "Elaboration of P3HT/CNT/PCBM composites for organic photovoltaic cells," Advanced Functional Materials, vol. 17, no. 16, pp. 3363-3370, 2007.

[46] S. Pan, Z. Yang, H. Li, L. Qiu, H. Sun, and H. Peng, "Efficient dye-sensitized photovoltaic wires based on an organic redox electrolyte," Journal of the American Chemical Society, vol. 135, no. 29, pp. 10622-10625, 2013.

[47] Z. B. Yang, J. Deng, X. L. Chen, J. Ren, and H. S. Peng, "A highly stretchable, fiber-shaped supercapacitor," Angewandte ChemieInternational Edition, vol. 52, no. 50, pp. 13453-13457, 2013.

[48] T. Chen, L. Qiu, Z. Yang et al., "An integrated "energy wire” for both photoelectric conversion and energy storage," Angewandte Chemie, vol. 51, no. 48, pp. 11977-11980, 2012.

[49] X. Chen, H. Sun, Z. Yang et al., "A novel "energy fiber" by coaxially integrating dye-sensitized solar cell and electrochemical capacitor," Journal of Materials Chemistry A, vol. 2, no. 6, pp. 1897-1902, 2014.

[50] Y.-L. Li, I. A. Kinloch, and A. H. Windle, "Direct spinning of carbon nanotube fibers from chemical vapor deposition synthesis," Science, vol. 304, no. 5668, pp. 276-278, 2004.

[51] X. Zhang, Q. Li, T. G. Holesinger et al., "Ultrastrong, stiff, and lightweight carbon-nanotube fibers," Advanced Materials, vol. 19, no. 23, pp. 4198-4201, 2007.

[52] X. Zhang, Q. Li, Y. Tu et al., "Strong carbon-nanotube fibers spun from long carbon-nanotube arrays," Small, vol. 3, no. 2, pp. 244-248, 2007.

[53] K. Koziol, J. Vilatela, A. Moisala et al., "High-performance carbon nanotube fiber," Science, vol. 318, no. 5858, pp. 1892-1895, 2007.

[54] H. Peng, "Aligned carbon nanotube/polymer composite films with robust flexibility, high transparency, and excellent conductivity," Journal of the American Chemical Society, vol. 130, no. 1, pp. 42-43, 2008.

[55] H. Peng, M. Jain, Q. Li, D. E. Peterson, Y. Zhu, and Q. Jia, "Vertically aligned pearl-like carbon nanotube arrays for fiber spinning," Journal of the American Chemical Society, vol. 130, no. 4, pp. 1130-1131, 2008.

[56] H. Peng, M. Jain, D. E. Peterson, Y. Zhu, and Q. Jia, "Composite carbon nanotube/silica fibers with improved mechanical strengths and electrical conductivities," Small, vol. 4, no. 11, pp. 1964-1967, 2008.

[57] H. Peng, X. Sun, F. Cai et al., "Electrochromatic carbon nanotube/polydiacetylene nanocomposite fibres," Nature Nanotechnology, vol. 4, no. 11, pp. 738-741, 2009.

[58] T. Chen, Z. Cai, Z. Yang et al., "Nitrogen-doped carbon nanotube composite fiber with a core-sheath structure for novel electrodes," Advanced Materials, vol. 23, no. 40, pp. 4620-4625, 2011.
[59] Z. B. Yang, X. M. Sun, X. L. Chen et al., "Dependence of structures and properties of carbon nanotube fibers on heating treatment," Journal of Materials Chemistry, vol. 21, no. 36, pp. 13772-13775, 2011.

[60] W. Guo, C. Liu, X. Sun, Z. Yang, H. G. Kia, and H. Peng, "Aligned carbon nanotube/polymer composite fibers with improved mechanical strength and electrical conductivity," Journal of Materials Chemistry, vol. 22, no. 3, pp. 903-908, 2012.

[61] L. Qiu, X. Sun, Z. Yang, W. Guo, and H. Peng, "Preparation and application of aligned carbon nanotube/polymer composite material," Acta Chimica Sinica, vol. 70, no. 14, pp. 1523-1532, 2012.

[62] Y. F. Luo, X. L. Wang, M. D. He, X. Li, and H. Chen, "Synthesis of high-quality carbon nanotube arrays without the assistance of water," Journal of Nanomaterials, vol. 2012, Article ID 542582, 5 pages, 2012.

[63] H. Qin, S. Wenger, M. Xu et al., "An organic sensitizer with a fused dithienothiophene unit for efficient and stable dye-sensitized solar cells," Journal of the American Chemical Society, vol. 130, no. 29, pp. 9202-9203, 2008.

[64] M. B. Schubert and J. H. Werner, "Flexible solar cells for clothing," Materials Today, vol. 9, no. 6, pp. 42-50, 2006.

[65] P. Xu, T. Gu, Z. Cao et al., "Carbon nanotube fiber based stretchable wire-shaped supercapacitors," Advanced Energy Materials, vol. 4, no. 3, 2014. 

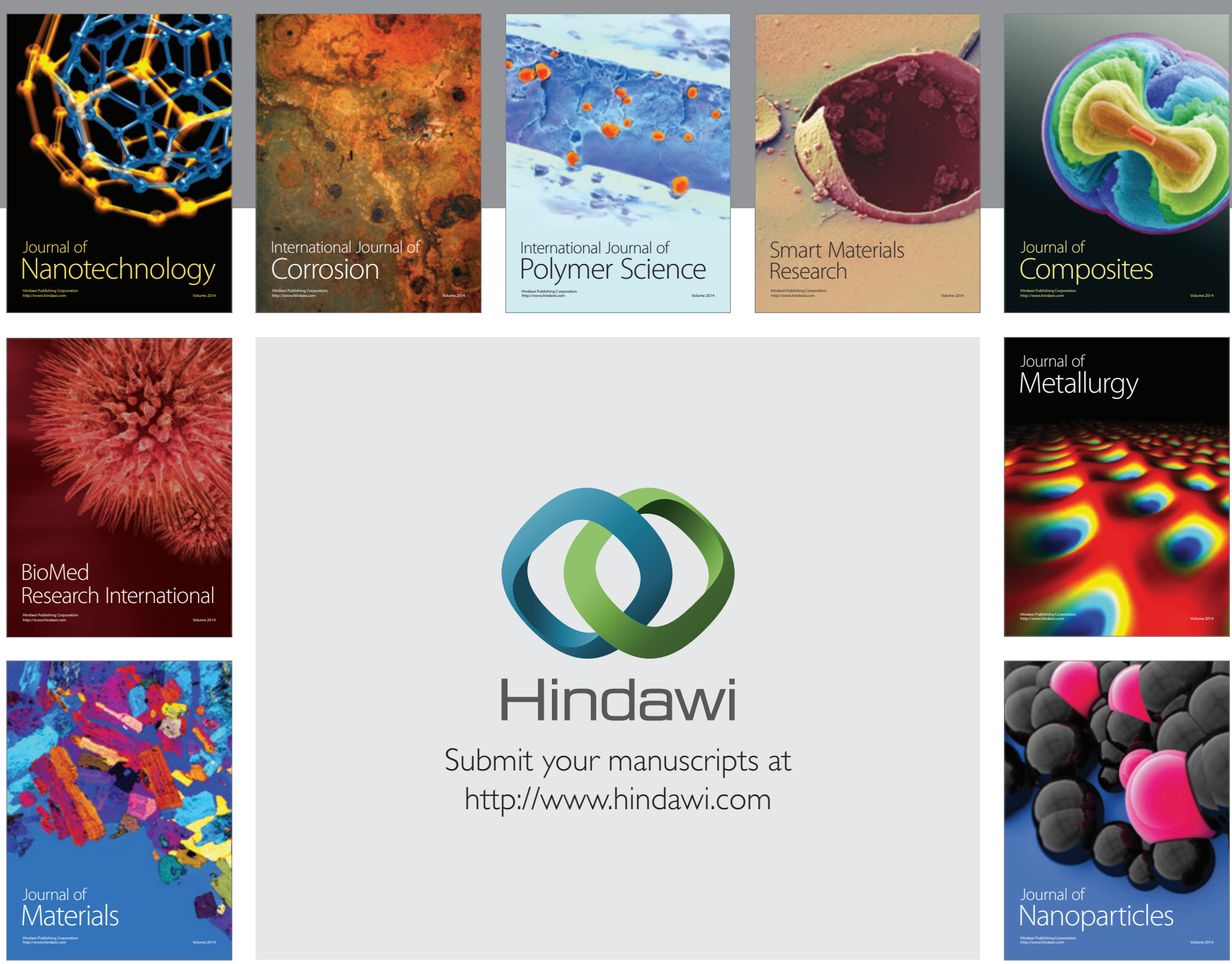

Submit your manuscripts at http://www.hindawi.com
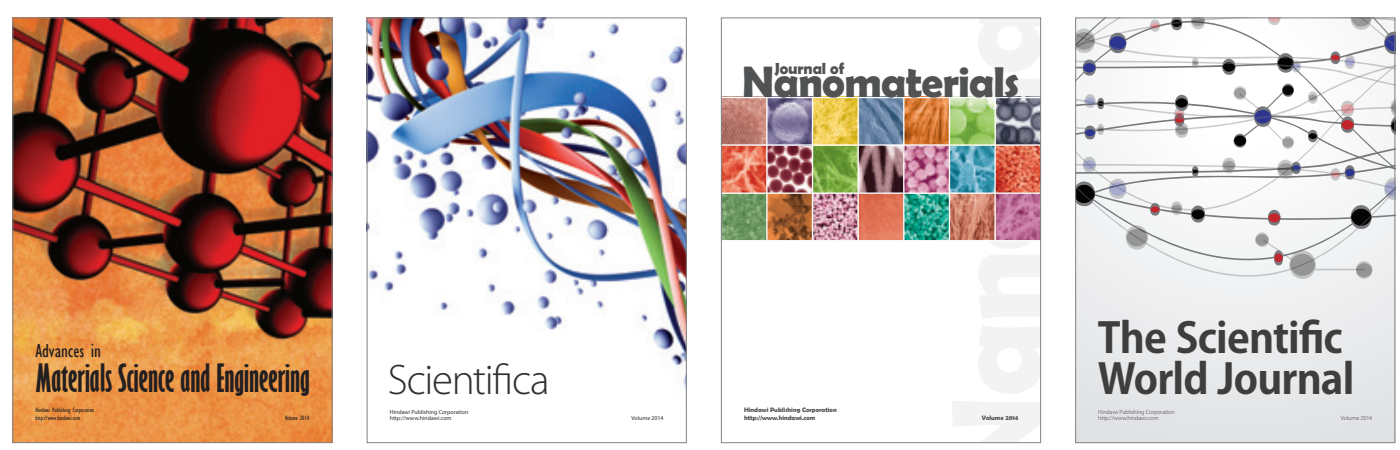

\section{The Scientific World Journal}
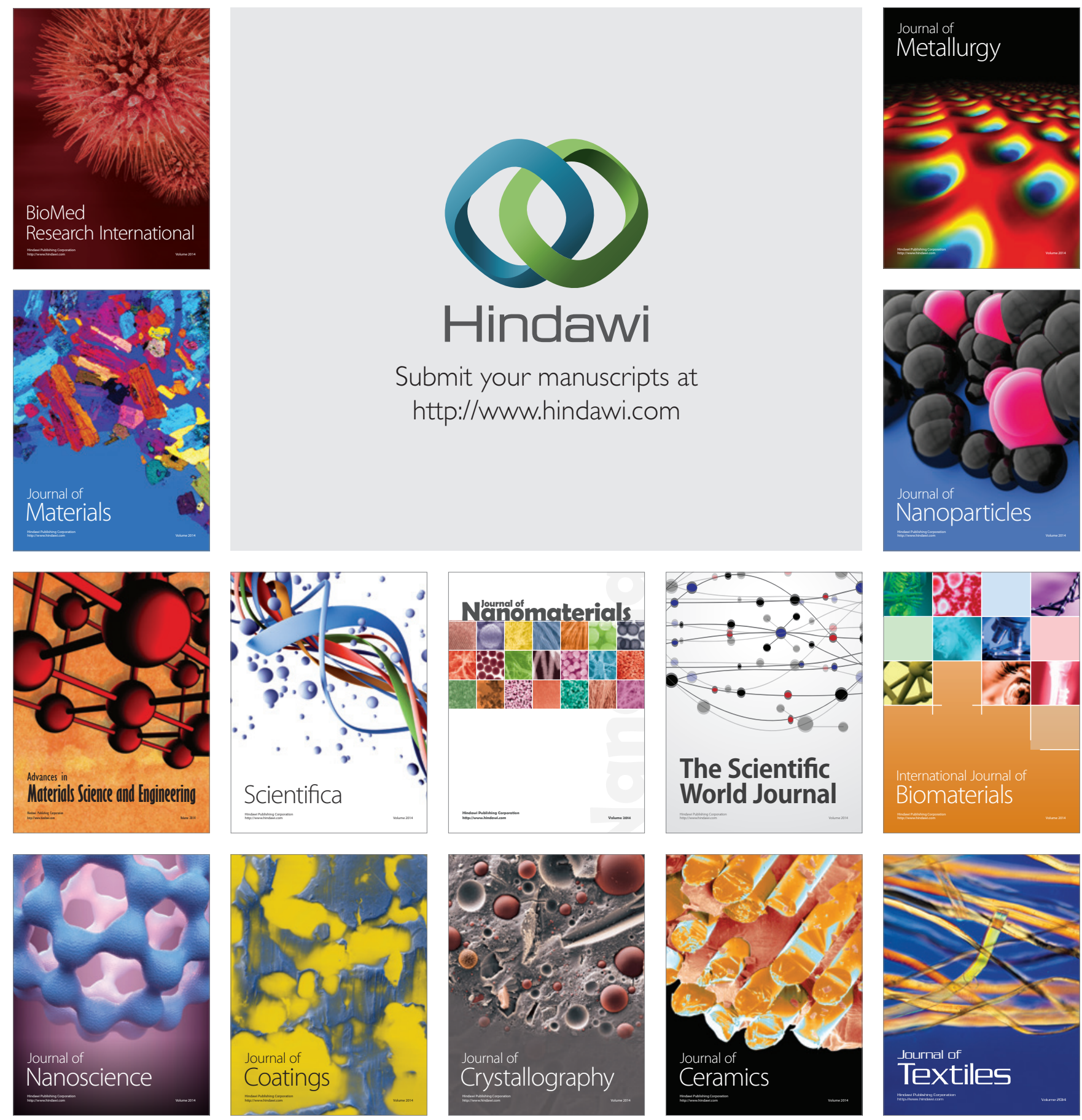